\title{
Medical Care of Adolescents and Women With Rett Syndrome: An Italian Study
}

\section{Aglaia Vignoli, ${ }^{1 *}$ Francesca La Briola, ${ }^{1}$ Angela Peron, ${ }^{1}$ Katherine Turner, ${ }^{1}$ Miriam Savini, ${ }^{1}$ Francesca Cogliati, ${ }^{2}$ Silvia Russo, ${ }^{2}$ and Maria Paola Canevini ${ }^{1}$}

\author{
${ }^{1}$ Neurology Unit, Epilepsy Center, University of Milan, Italy \\ ${ }^{2}$ Molecular Genetics Laboratory, Istituto Auxologico Italiano, Milan Italy
}

Received 15 December 2010; Accepted 11 October 2011

Rett syndrome (RTT) is a rare neurodevelopmental disorder, linked to MECP2 gene mutations in the majority of cases, which results in severe disability and is associated with several comorbidities. The clinical condition of RTT patients tends to stabilize over time, and prolonged survival has recently been demonstrated. However, limited information is available on the longterm course of older patients with RTT, especially among those in Southern Europe. The aim of our study is to evaluate the main clinical features and state of health of adult Italian patients with RTT and to present their evolution over time, identifying major clinical issues present at different ages. A total of 130 families of patients with RTT aged $\geq 14$ years were asked to complete a questionnaire, 84 of which were returned (65\%). Among the clinical characteristics of RTT, stereotypies and poor hand function and feeding ability remained stable over time, while nonverbal communication tended to improve. With regard to the main pathologies, sleep, behavioral, and autonomic disorders persisted into adulthood, while epilepsy improved and musculoskeletal problems worsened. In our sample, older patients with R294X and R133C mutations and with C-terminal deletions showed lower levels of clinical severity. The development of guidelines for the clinical management of patients with RTT will assist health care providers in dealing with the complex RTT phenotype. More extensive data about the long-term course of the condition could help in the design of programs for secondary prevention of disabilities for younger females affected by the syndrome. $\odot 2011$ Wiley Periodicals, Inc.

Key words: Rett syndrome; adult phenotype; comorbidities; clinical management

\section{INTRODUCTION}

Recent years have witnessed improvements in health care for people with intellectual disabilities as their life expectancy has increased, but experience with adult patients with genetic syndromes is still limited; thus, their needs are not always addressed. Moreover, patients with intellectual disabilities often have multiple medical issues. For these reasons, recognition of the clinical and behavioral characteristics of specific syndromes and their age-dependent course is needed to meet the needs of adult patients.
How to Cite this Article:

A Vignoli, FL Briola, A Peron, K Turner, M Savini, F Cogliati, S Russo, MP Canevini, 2012. Medical care of adolescents and women with Rett syndrome: An Italian study.

Am J Med Genet Part A 158A:13-18.

Rett syndrome (RTT) is a neurodevelopmental disorder almost exclusively affecting females, with an incidence ranging from $1 / 10,000$ to $1 / 15,000$. More than $70 \%$ of cases have mutations in MECP2 (Methyl CpG Binding protein2), a transcriptional repressor gene located in Xq28 [Colvin et al., 2003].

Recently, other genes have been identified as responsible for the early [Archer et al., 2006; Bahi-Buisson et al., 2008; Artuso et al., 2010] and the congenital [Mencarelli et al., 2010] variant of the syndrome.

Clinical presentation of classical RTT usually occurs in the first years of life with regression of early acquired developmental skills, such as speech and motor functions, and, in particular, loss of purposeful hand use. The period of regression is usually followed by a "wake-up" period associated with some communicative restitution and preserved ambulant ability. This stage can last for a variable period and may be followed by late motor deterioration, mainly involving gross motor functions [Hagberg, 2002].

It is now well known that the clinical condition of RTT patients tends to stabilize over time, and their potential for prolonged survival has recently been demonstrated [Freilinger et al., 2010; Kirby et al., 2010]. However, the long term-course of older patients with RTT has not been well studied, especially among patients in Southern Europe.

${ }^{\star}$ Correspondence to:

Aglaia Vignoli, MD, Centro Epilessia Ospedale San Paolo-Università degli Studi di Milano Via di Rudinì, 820142 Milano, Italy

E-mail: aglaia.vignoli@ao-sanpaolo.it

Published online 2 December 2011 in Wiley Online Library

(wileyonlinelibrary.com).

DOI 10.1002/ajmg.a.34367 
The aim of our study is to evaluate the main clinical features and state of health of adult Italian patients with RTT and to present their evolution over time, identifying major clinical issues that arise at different ages.

\section{METHODS}

\section{Study Design}

A questionnaire designed to identify the clinical features and main pathologies among adult RTT patients was sent to all members of the Italian Association for Rett Syndrome (AIR) who have children aged $\geq 14$ years. A list of items describing demographic, social, and clinical assessment was developed based on current literature and clinicians' experience with RTT female patients. The patients were divided into three age groups: 14-20 years (group 1), 21-29 years (group 2), and over 29 years (group 3). A modified Kerr score was used to assess the severity of the disease for each patient [Kerr et al., 2001]: clinical features including musculoskeletal problems, gross motor function, hand stereotypies, voluntary hand use, oromotor difficulties, speech, epilepsy, breathing rhythm, peripheral circulation, mood disturbances, sleep disturbances, gastrointestinal problems, and sitting positions were evaluated, and different degrees of severity were assigned to each patient, between 0 to 1 and 0 to 3 , according to severity. A higher severity score corresponded to a worse state of health.

Other than the Kerr score, parameters related to growth were not taken into consideration.

\section{Sample}

One-hundred thirty families of AIR were asked to complete an anonymous questionnaire.

Of these, 84 questionnaires were returned (65\%). Most of the questionnaires were filled in by the parents of the patients.

\section{Demographic and Social Variables}

The first part of the questionnaire included questions regarding demographic and social variables: we asked the families how old the RTT patients were at the time of the study, if they lived at home or in a facility, if they attended a day care center, if they followed any rehabilitation program and what kind of school they were attending or had attended. Information on the genetic diagnosis was also requested, if available.

\section{Clinical Variables}

Questions concerning clinical characteristics and main pathologies were asked in the second part of the questionnaire.

Regarding clinical characteristics, we investigated stereotypies, gross motor functions, communication skills, and feeding. For each item, the parents were asked whether their daughter's functions were normal or impaired, or if functions were lost or never acquired; they were also asked to judge whether the problem had remained stable, improved or worsened after 14 years of age.

Regarding the main pathologies, we investigated epilepsy, sleep disorders, behavioral problems, autonomic disorders, gastrointestinal disorders, and musculoskeletal problems. The parents were asked whether each problem was absent, mild, moderate, or severe. Parents were also asked to judge the course of the problems after 14 years of age, selecting among three choices: stable, improved, or worsened.

Finally, questions were asked about hospitalization and emergency room admission in adolescence and adult age, with a focus on the main reason for taking the patient to the hospital.

\section{Statistical Analysis}

Data were transferred into an electronic database and processed by Statistical Package for the Social Sciences for Windows (SPSS 18). Significance was set at a $P$-value of 0.05 . Prevalence rates were calculated for clinical characteristics and continuous variables were presented as means and standard deviations (SD). Clinical characteristics of the three age groups were analyzed using Chi square Tests. Severity score differences between the three groups and mutation types were assessed with the ANOVA.

\section{RESULTS}

\section{Demographic and Social Variables}

Mean age at time of the study was 24 years (range $14-42$ years, SD 6.7). Mutation analysis had been performed on 76 (90\%): 16 patients did not show any mutation (21\%); of the remaining cases, 59 MECP2 mutations were identified (78\%) (Table I) and one patient had a CDKL5 mutation (1\%).

Most of the patients lived at home $(\mathrm{n}=81,96 \%)$, and three lived in residential facilities (4\%). Fifty patients $(60 \%)$ attended a day care center.

Compulsory school was completed by most of the patients $(n=60,71 \%)$. Seventy-two patients participated in a rehabilitation program $(86 \%)$, consisting of physical therapy $(n=48,57 \%)$, hydrotherapy $(\mathrm{n}=47,56 \%)$, horseback riding $(\mathrm{n}=19,23 \%)$,

TABLE I. Types and Frequencies of MECP2 Mutations Among Persons With Rett Syndrome

MECP2 mutation type
R270X, R255X, 750insC
C-terminal
R294X
R168X, Y141X
R306C
T158M
Del exons 3 and 4
R133C
P152R
P322A
R106W
P225R
T158A
A2V
Unknown or not specified

$\%$ [of 59 with MECP2 mutation] 22 13.6 10.2 8.4 8.4 6.8 5.1 5.1 3.5 1.7 1.7 1.7 1.? 1.7 8.4 
and music therapy $(\mathrm{n}=20,24 \%)$. Augmentative communication was utilized by 44 patients (52\%).

\section{Clinical Variables}

Stereotypies. Hand stereotypies were present in 81 patients $(98 \%)$. The stereotyped movements usually involved both hands and were most frequently described as mouthing $(\mathrm{n}=28,35 \%)$ and hand washing $(\mathrm{n}=27,33 \%)$.

Use of the hands was never acquired in nine patients (11\%), lost in $33(39 \%)$, and impaired in 37 (44\%). Function was preserved in five patients $(6 \%)$.

Gross motor function. Independent walking was possible for 17 RTT patients $(20 \%)$, while 67 patients $(80 \%)$ showed varying degrees of problems with ambulation: 19 (23\%) never acquired this function, $13(16 \%)$ were able to walk but lost this ability (mean age of loss 11.3 years, range $3-28)$, and the remaining 35 (41\%) of the patients were able to walk with assistance.

Sitting was considered normal in 31 women (37\%), while in 53 patients $(63 \%)$ this ability was impaired (5 patients [6\%] never acquired this function).

Communication. Communication abilities were classified as verbal and nonverbal. Preserved speech was present in only three patients $(4 \%)$, while 10 women $(12 \%)$ spoke a few words. In the majority of RTT patients $(n=42,50 \%)$, language was acquired and subsequently lost (mean age at loss 2.8 years, range 14 months to 9 years). The remaining 29 women (35\%) never acquired the ability to speak. However, nonverbal communication was reported in 64 patients $(76 \%)$, mainly through eye contact. Among those whose nonverbal communication was compromised, 12 patients $(60 \%)$ demonstrated improvement over time.

Feeding. Feeding was considered normal in more than half of the sample ( $\mathrm{n}=45,54 \%)$; among these patients, $62(75 \%)$ were able to chew and 26 (31\%) could bring food to the mouth themselves. Three patients required percutaneous endoscopic gastrostomy (PEG) placement.

The course of the clinical characteristics is described in Figure 1.

\section{Main Pathologies}

Epilepsy. A seizure disorder was reported in 69 patients (82\%), with a mean age at onset of 5 years (range 1-16 years). Seizures were controlled by medications in 28 patients $(41 \%)$, while in five patients $(7 \%)$ antiepileptic therapy was withdrawn without recurrence. Eleven patients (16\%) presented only sporadic seizures.

Epilepsy was drug-resistant in 25 patients (36\%), with the need for an antiepileptic polytherapy in most cases $(60 \%)$. Twenty-five patients with epilepsy (36\%) experienced status epilepticus at least once in their life.

Sleep disorders. Sleep disorders were reported in the majority of patients $(n=65,77 \%)$, even if considered a mild problem by the parents. The most frequent disorder was night waking $(\mathrm{n}=47$, $56 \%)$, followed by precocious morning waking $(\mathrm{n}=29,35 \%)$ and resistance to falling asleep $(n=19,23 \%)$. To limit or avoid sleep disorders, 31 patients $(48 \%)$ were on therapy with melatonin or niaprazine.

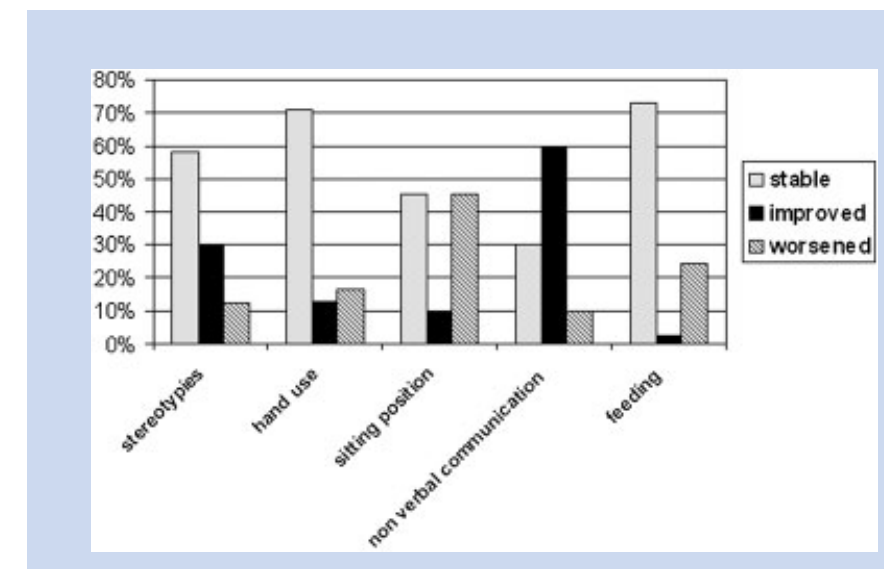

FIG. 1. Course of the clinical characteristics among persons with Rett syndrome after 14 years of age.

Behavioral problems. Behavioral disorders were present in 58 patients $(69 \%)$, mainly agitation $(n=39,46 \%)$ and depressed $\operatorname{mood}(\mathrm{n}=36,43 \%)$.

Autonomic disorders. Breathing anomalies were present in 59 patients $(70 \%)$, mainly apnea $(\mathrm{n}=48,57 \%)$ and hyperventilation $(\mathrm{n}=30,36 \%)$. Heart arrhythmias, documented by ECG anomalies, were reported in 15 women (18\%).

A majority of patients suffered from vasculocutaneous disorders $(\mathrm{n}=77,92 \%)$ : cold feet were described in 73 patients $(87 \%)$, cyanotic extremities in $30(36 \%)$, atrophic skin and nail modifications in 17 (20\%).

Gastrointestinal disorders. Gastrointestinal disturbances have a high prevalence in our sample $(\mathrm{n}=75,89 \%)$, and required therapies in $54 \%(n=45)$. Constipation was the most frequent disorder $(\mathrm{n}=71,85 \%)$. Gastroesophageal reflux was reported in 21 $(25 \%)$ of the patients and tended to improve over time $(P=0.003)$.

Musculoskeletal problems. Musculoskeletal problems were often experienced $(\mathrm{n}=81,96 \%)$, scoliosis being the most frequent problem reported $(\mathrm{n}=70,83 \%)$. Reported disorders also included spasticity $(n=43,51 \%)$ and joint deformities $(n=30,36 \%)$, the latter significantly worsening with increasing age $(P=0.028)$.

Osteoporosis was reported in 38 women (45\%) and was documented by dual energy X-ray absorptiometry scanning in all of these.

The course of the main disorders is described in Figure 2.

\section{Age Groups and Severity Score}

We found a statistically significant difference in severity scores among the three groups $(P<0.05)$. Specifically, a significant difference was noted between group 1 (14-20 years, mean severity score 17.73 ) and group 3 ( $>29$ years, mean severity score 14.95 ), the older group having a less severe score, with a $P$-value of 0.018 , and between group 2 (21-29 years, mean severity score 18.77 ) and group 3, the older group having a less severe score, with a $P$-value of 0.002 . 


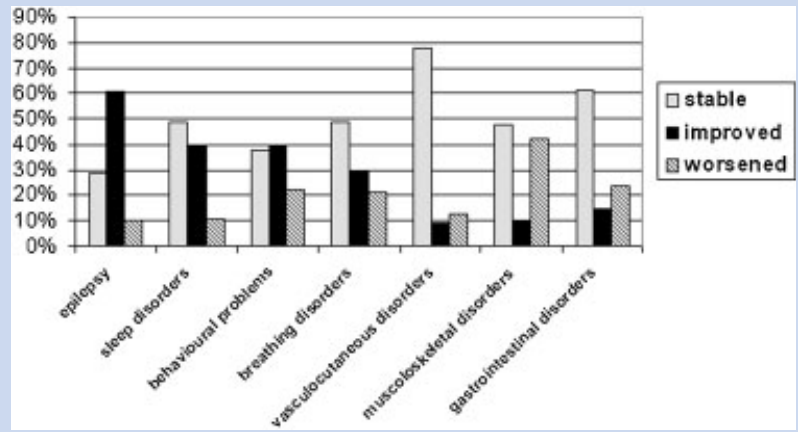

FIG. 2. Course of health issues among persons with Rett syndrome after 14 years of age.

\section{Mutation Type and Severity Score}

No statistically significant difference between mutation type and severity score was found. However, we were able to describe different scores for different mutations: the lower score (corresponding to a less impaired state of health) was found in patients with C-terminal deletions ( $($ core $=15.88)$ and with R294X ( score $=15.17)$ and $\mathrm{R} 133 \mathrm{C}($ score $=12.33)$ mutations, while a higher score was found in patients with large deletions of exons 3 and 4 (score $=19.00)$, in patients with R270X, R255X, 750insC $($ score $=18.54)$, and in those without a molecular diagnosis $($ score $=18.63)$.

\section{Hospitalization}

Most patients $(\mathrm{n}=55,66 \%)$ had been admitted to the hospital for clinical and instrumental follow-up or for emergency reasons at least once. Emergency room care was reported for 31 patients (37\%): the main reasons were trauma and/or bone fractures $(\mathrm{n}=12,39 \%)$ and seizures $(\mathrm{n}=9,29 \%)$.

\section{DISCUSSION}

As survival improves, clinicians are increasingly faced with caring for adults with genetic syndromes. Clinical management of their medical problems is often challenging. The long-term course of RTT has been described in different groups of patients from North America [Kirby et al., 2010], Australia [Moore et al., 2005], Sweden [Hagberg, 2005], the United Kingdom [Cass et al., 2003] and the Netherlands [Halbach et al., 2008; Smeets et al., 2009], but the description of adult patients with RTT from Southern Europe has been lacking. Our study provides information on these patients, including clinical and behavioral problems identified among patients of RTT at different ages. These findings could be used to design specific intervention programs for adults with RTT.

Our response rate was relatively high $(65 \%)$, suggesting that the respondents were highly motivated to provide information about RTT to researchers. However, our study has inherent limitations. Specifically, data were obtained from the patients' parents in most cases, and parents may misreport some clinical details. It is possible that those who completed the survey may be different from those who refused (e.g., they may put more effort into their daughters' care, and thus, their health might be better: this could result in a potential bias).

Based on our results and those of the recent literature [Vignoli et al., 2009; Carter et al., 2010], it appears that stereotypies tend to persist over time. Hand function may be able to be maintained, even though impaired, in half of our patients. This skill should be developed as much as possible, since patients may be able to perform some functions themselves (e.g., a third of our sample are able to bring food to their mouths on their own).

On the other hand, gross motor skills tend to worsen over time [Downs et al., 2008a]; independent ambulation or at least ambulation with support should be encouraged as long as possible. The maintenance of this ability is important both for the care of the patients as well as for maintaining their personal interests and providing appropriate stimuli.

Relevant consideration should be addressed to communication abilities in RTT. Although expressive language is often lost in the early stage of the disease, comprehension skills can be maintained. Moreover, nonverbal abilities can be developed and can also improve over time, as previously described and shown in our study [Fontanesi and Haas, 1988; Halbach et al., 2008; Fabio et al., 2009].

Considering the main diseases involving adult RTT patients, epilepsy still represents a major concern, since a seizure disorder has been experienced by $81 \%$ of the patients. This high percentage is consistent with previous studies [Jian et al., 2007; Halbach et al., 2008; Smeets et al., 2009; Pintaudi et al., 2010], although it may be that seizures are over reported [Glaze et al., 2010].

Our data confirms that more than third of females with RTT have drug-resistant epilepsy, which usually requires antiepileptic drug polytherapy and can be complicated by status epilepticus. In addition, the possibility of withdrawing antiepileptic therapy in selected patients should be considered, as also suggested by other authors [Lotan et al., 2010].

Families of RTT patients have to deal with sleep and behavioral problems; melatonin seems to be effective in regulating the sleep cycle in these patients [McArthur and Budden, 1998; Miyamoto et al., 1999] and is widely used in our sample. Behavioral disorders are more difficult to control and studies in this field are lacking. Regarding autonomic disturbances, our data confirm that these are still present in adulthood, as previously described [Cass et al., 2003; Halbach et al., 2008].

One of the most striking issues in adult patients was scoliosis: guidelines for management of this specific problem have recently been developed [Downs et al., 2009]. Intensive physical therapy and other preventive measures should be provided for scoliosis, as reported by Lotan et al. [2005], but also for joint deformities, which tend to worsen over time.

Moreover, patients with RTT show a high risk of fractures due to early onset osteoporosis, as previously stated for the Australian population. Intervention to prevent fractures should be considered [Downs et al., 2008b; Motil et al., 2008].

In comparison to other groups of RTT patients where $20 \%$, mainly in the older age group, had enteral nutrition support [Oddy et al., 2007], feeding ability was considered adequate in more than half of our patients, with only three patients needing the positioning 
of a PEG. Nevertheless, gastrointestinal problems are major issues in the RTT population, with constipation and gastroesophageal reflux being the most frequently reported. Medical therapy should be addressed to prevent worsening of these issues, and feeding programs should be developed to avoid malnutrition and its consequences [Oddy et al., 2007; Motil et al., 2009; Prior et al., 2010].

Patients in the oldest age group ( $>29$ years) had statistically significant less severe scores than the patients in the two younger groups: this could be explained by the fact that the patients with more severe conditions died before reaching their thirties, and only patients with a milder phenotype survived. These findings are consistent with current literature [Colvin et al., 2004; Bebbington et al., 2010] and corroborate the evidence that older patients with RTT have a milder phenotype.

Although it was difficult to assess statistically significant differences between individual mutations due to power limitations, patients with C-terminal deletions and R294X and R133C mutations had lower severity scores, while patients carrying large deletions and patients without mutations were more severely affected. Our finding that patients without mutations have a more severe phenotype is consistent with a previous study by Temudo et al. [2011]. It is also possible that the patients without mutations underwent molecular testing before Multiplex Ligation-dependent Probe Amplification was introduced in routine analysis. These patients may have large deletions that were missed on earlier testing [Scala et al., 2007], explaining our findings of a more impaired state of health in them.

We believe that the complex phenotype of RTT requires more extensive medical care and that guidelines for clinical management of adolescent and adult patients with RTT are needed. Our study provides insight into the main problems of RTT in adulthood and may be helpful in addressing appropriate therapies. However, given our study's limitations, we encourage further longitudinal studies to collect more extensive data about the long-term course of the syndrome, which may be helpful in the design of intervention programs for younger patients with RTT.

\section{ACKNOWLEDGMENTS}

The authors would like to acknowledge all the patients and families from AIR (Italian Association for Rett Syndrome) who helped us carry out the study.

\section{REFERENCES}

Archer HL, Evans J, Edwards S, Colley J, Newbury-Ecob R, O'Callaghan F, Huyton M, O’Regan M, Tolmie J, Sampson J, Clarke A, Osborne J. 2006. CDKL5 mutations cause infantile spasms, early onset seizures, and severe mental retardation in female patients. J Med Genet 43:729-734.

Artuso R, Mencarelli MA, Polli R, Sartori S, Ariani F, Pollazzon M, Marozza A, Cilio MR, Specchio N, Vigevano F, Vecchi M, Boniver C, Dalla Bernardina B, Parmeggiani A, Buoni S, Hayek G, Mari F, Renieri A, Murgia A. 2010. Early-onset seizure variant of Rett syndrome: Definition of the clinical diagnostic criteria. Brain Dev 32:17-24.

Bahi-Buisson N, Nectoux J, Rosas-Vargas H, Milh M, Boddaert N, Girard B, Cances C, Ville D, Afenjar A, Rio M, Héron D, N'guyen Morel MA,
Arzimanoglou A, Philippe C, Jonveaux P, Chelly J, Bienvenu T. 2008. Key clinical features to identify girls with CDKL5 mutations. Brain 131:2647-2661.

Bebbington A, Percy A, Christodoulou J, Ravine D, Ho G, Jacoby P, Anderson A, Pineda M, Ben Zeev B, Bahi-Buisson N, Smeets E, Leonard H. 2010. Updating the profile of C-terminal MECP2 deletions in Rett syndrome. J Med Genet 47:242-248.

Carter P, Downs J, Bebbington A, Williams S, Jacoby P, Kaufmann WE, Leonard H. 2010. Stereotypical hand movements in 144 subjects with Rett syndrome from the population-based Australian database. Mov Disord 25:282-288.

Cass H, Reilly S, Owen L, Wisbeach A, Weekes L, Slonims V, Wigram T, Charman T. 2003. Findings from a multidiscinary clinical case series of females with Rett syndrome. Dev Med Child Neurol 45:325-337.

Colvin L, Fyfe S, Leonard S, Schiavello T, Ellaway C, de Klerk N, Christodoulou J, Msall M, Leonard H. 2003. Describing the phenotype in Rett syndrome using a population database. Arch Dis Child 88: $38-43$.

Colvin L, Leonard H, de Klerk N, Davis M, Weaving L, Williamson S, Christodoulou J. 2004. Refining the phenotype of common mutations in Rett syndrome. J Med Genet 41:25-30.

Downs JA, Bebbington A, Jacoby P, Msall ME, Mcllroy O, Fyfe S, Bahi-Buisson N, Kaufmann WE, Leonard H. 2008a. Gross motor profile in Rett syndrome as determined by video analysis. Neuropediatrics 39:205-210.

Downs J, Bebbington A, Woodhead H, Jacoby P, Jian L, Jefferson A, Leonard H. 2008b. Early determinants of fractures in Rett syndrome. Pediatrics 121:540-546.

Downs J, Bergman A, Carter P, Anderson A, Palmer GM, Roye D, van Bosse H, Bebbington A, Larsson EL, Smith BG, Baikie G, Fyfe S, Leonard H. 2009. Guidelines for management of scoliosis in Rett syndrome patients based on expert consensus and clinical evidence. Spine 34:E607-E617.

Fabio RA, Antonietti A, Castelli I, Marchetti A. 2009. Attention and communication in Rett syndrome. Res Autism Spectr Disord 3:329-335.

Fontanesi J, Haas RH. 1988. Cognitive profile of Rett sindrome. J Child Neurol 3:S20-S24.

Freilinger M, Bebbington A, Lanator I, De Klerk N, Dunkler D, Seidl R, Leonardo H, Ronen GM. 2010. Survival with Rett syndrome: Comparing Rett's original sample with data from the Australian Rett syndrome database. Dev Med Child Neurol 52:962-965.

Glaze DG, Percy AK, Skinner S, Motil KJ, Neul JL, Barrish JO, Lane JB, Geerts SP, Annese F, Graham J, McNair L, Lee HS. 2010. Epilepsy and the natural history of Rett syndrome. Neurology 74:909-912.

Hagberg B. 2002. Clinical manifestations and stages of Rett Syndrome. Ment Retard Dev Dis Res Rew 8:61-65.

Hagberg B. 2005. Rett syndrome: Long term clinical follow-up experiences over four decades. J Child Neurol 20:722-727.

Halbach NSJ, Smeets EEJ, Schrander-Stumpel CTRM, van Schrojenstein Lantman de Valk HHJ, Maaskant MA, Curfs LMG. 2008. Aging in people with specific genetic syndromes: Rett syndrome. Am J Med Genet Part A 146A:1925-1932.

Jian L, Nagarajan L, de Klerk N, Ravine D, Christodoulou J, Leonard H. 2007. Seizures in Rett syndrome: An overview from a one-year calendar study. Eur J Paediatr Neurol 11:310-317.

Kerr AM, Nomura Y, Armstrong D, Anvret M, Belichenko PV, Budden S, Cass H, Christodoulou J, Clarke A, Ellaway C, d'Esposito M, Francke U, Hulten M, Julu P, Leonard H, Naidu S, Schanen C, Webb T, Engerstrom IW, Yamashita Y, Segawa M. 2001. Guidelines for reporting clinical features in cases with MECP2 mutations. Brain Dev 23:208-211. 
Kirby RS, Lane JB, Childers J, Skinner SA, Annese F, Barrish JO, Glaze DG, MacLeod P, Percy AK. 2010. Longevity in Rett syndrome: Analysis of the North American database. J Pediatr 156:135-138.

Lotan M, Merrick J, Carmeli E. 2005. Managing scoliosis in a young child with Rett syndrome: A case study. Sci World J 5:264-273.

Lotan M, Merrick J, Kandel I, Morad M. 2010. Aging in persons with Rett syndrome: An updated review. Sci World J 10:778-787.

McArthur AJ, Budden SS. 1998. Sleep dysfunction in Rett syndrome: A trial of exogenous melatonin treatment. Dev Med Child Neurol 40:186-192.

Mencarelli MA, Spanhol-Rosseto A, Artuso R, Rondinella D, De Filippis R, Bahi-Buisson N, Nectoux J, Rubinsztajn R, Bienvenu T, Moncla A, Chabrol B, Villard L, Krumina Z, Armstrong J, Roche A, Pineda M, Gak E, Mari F, Ariani F, Renieri A. 2010. Novel FOXG1 mutations associated with the congenital variant of Rett syndrome. J Med Genet 47:49-53.

Miyamoto A, Oki J, Takahashi S, Okuno A. 1999. Serum melatonin kinetics and long-term melatonin treatment for sleep disorders in Rett syndrome. Brain Dev 21:59-62.

Moore H, Leonard H, de Klerk N, Robertson I, Fyfe S, Christodoulou J, Weaving L, Davis M, Mulroy S, Colvin L. 2005. Health service use in Rett syndrome. J Child Neurol 20:42-50.

Motil KJ, Ellis KJ, Barrish JO, Caeg E, Glaze DG. 2008. Bone mineral content and bone mineral density are lower in older than in younger females with Rett syndrome. Pediatr Res 64:435-439.

Motil KJ, Morrissey M, Caeg E, Barrish JO, Glaze DG. 2009. Gastrostomy placement improves height and weight gain in girls with Rett syndrome. J Pediatr Gastroenterol Nutr 49:237-242.
Oddy WH, Webb KG, Baikie G, Thompson SM, Reilly S, Fyfe SD, Young S, Anderson AM, Leonard H. 2007. Feeding experiences and growth status in a Rett syndrome population. J Pediatr Gastroenterol Nutr 45:582-590.

Pintaudi M, Calevo MG, Vignoli A, Parodi E, Aiello F, Baglietto MG, Hayek J, Buoni S, Renieri A, Russo S, Cogliati F, Giordano L, Canevini MP, Veneselli E. 2010. Epilepsy in Rett syndrome: Clinical and genetic features. Epilepsy Behav 19:296-300.

Prior C, Nunes A, Rios M, Sequeiros J, Maciel P, Gomes L, Temudo T. 2010. Nutrition and gastrointestinal disorders in Rett syndrome: Importance of early intervention. An Pediatr (Barc) 72:191-198.

Scala E, Longo I, Ottimo F, Speciale C, sampieri K, Katzaki E, Artuso R, Mencarelli MA, D'Ambrogio T, Vonella G, Zappella M, Hayek G, Battaglia A, Mari F, Renieri A, Ariani F. 2007. MECP2 deletions and genotype-phenotype correlation in Rett syndrome. Am J Med Genet Part A 143A:2775-2784.

Smeets EEJ, Chenault M, Curfs LMG, Schrander-Stumpel CTRM, Frijns JP. 2009. Rett syndrome and long-term disorders profile. Am J Med Genet Part A 149A:199-205.

Temudo T, Santos M, Ramos E, Dias K, Vieira JP, Moreira A, Calado E, Carrilho I, Oliveira G, Levy A, Barbot C, Fonseca M, Cabral A, Cabral P, Monteiro J, Borges L, Gomes R, Mira G, Aires Pereira S, Santos M, Fernandes A, Epplen JT, Sequeiros J, Maciel P. 2011. Rett syndrome with and without detected MECP2 mutations: An attempt to redefine phenotypes. Brain Dev 33:69-76.

Vignoli A, La Briola F, Canevini MP. 2009. Evolu tion of stereotypies in adolescents and women with Rett syndrome. Mov Disord 24: 1379-1383. 